\title{
Powder and Solvent for Solution for Injection in Cartridge
}

National Cancer Institute

\section{Source}

National Cancer Institute. Powder and Solvent for Solution for Injection in Cartridge. NCI

Thesaurus. Code C149797.

Medicinal product consisting of a powder and solvent for solution for injection presented in a cartridge. The powder and solvent are contained in different compartments of the cartridge, which contains all of the components necessary to prepare the solution for injection. 